\title{
Latent 1500-year climate oscillation in the Holocene
}

\author{
Masanobu Yamamoto \\ Faculty of Environmental Earth Science, Hokkaido University, Sapporo, Japan; myama@ees.hokudai.ac.jp
}

\begin{abstract}
A Holocene temperature record from the Japan margin shows a significant 1500 -year period, suggesting the existence of a persistent cycle since the last glacial period.
\end{abstract}

S uborbital climate variability during the last glacial period has been suggested to be paced with a 1500-year period, but the expression and spatial distribution of this oscillation during interglacials remain unclear. Millennialscale variations during the Holocene were first reported by Bond et al. (1997) based on ice-rafted hematite-stained grains (HSG) in North Atlantic sediments. Although spectral analyses did not yield a significant 1500-year period, the abundance of these grains peaked on average every 1.5 millennia (Bond et al. 2001). However, few other climate records have shown a clear 1500-year periodicity in the Holocene.

Here, I discuss 1500-year variability found in a multi-decadally resolved Holocene record of alkenone sea-surface temperatures (SST) from the northwestern Pacific off central Japan (Isono et al. 2009). In that region warm waters of the Kuroshio Current mix with cold waters of the Oyashio Current (Fig. 1).

\section{A Holocene 1500-year cycle off Japan}

Detrended SST variations at Site MD012421 show a series of SST minima (Fig. $2 \mathrm{~A}$; Isono et al. 2009). The youngest of them, centered at $\sim 0.3 \mathrm{ka}$ and $\sim 1.5 \mathrm{ka}$, occur around the time of the Little Ice Age and the Dark Ages Cold Period in Europe, respectively. Spectral analysis of SST over the last $10.8 \mathrm{ka}$ revealed a statistically significant periodicity of 1470 years. One cooling period at $8.5 \mathrm{ka}$ is not consistent with the $\sim 1500$-year cycle, but might correspond with the 8.2-ka cooling event (Alley et al. 1997).

With the exception of the cooling event at $8.5 \mathrm{ka}$, the SST minima re-occur at intervals of 1.1-1.7 ka. In the 400year running average of the detrended SST (Fig. 2B) the standard deviations for warming (i.e. mid-point between maximum and minimum SST), warmest, cooling, and coldest events of the last seven cycles from the 1470-year templates are $112,237,245$, and 160 years, respectively. This implies that the periodicity is most stable for warming

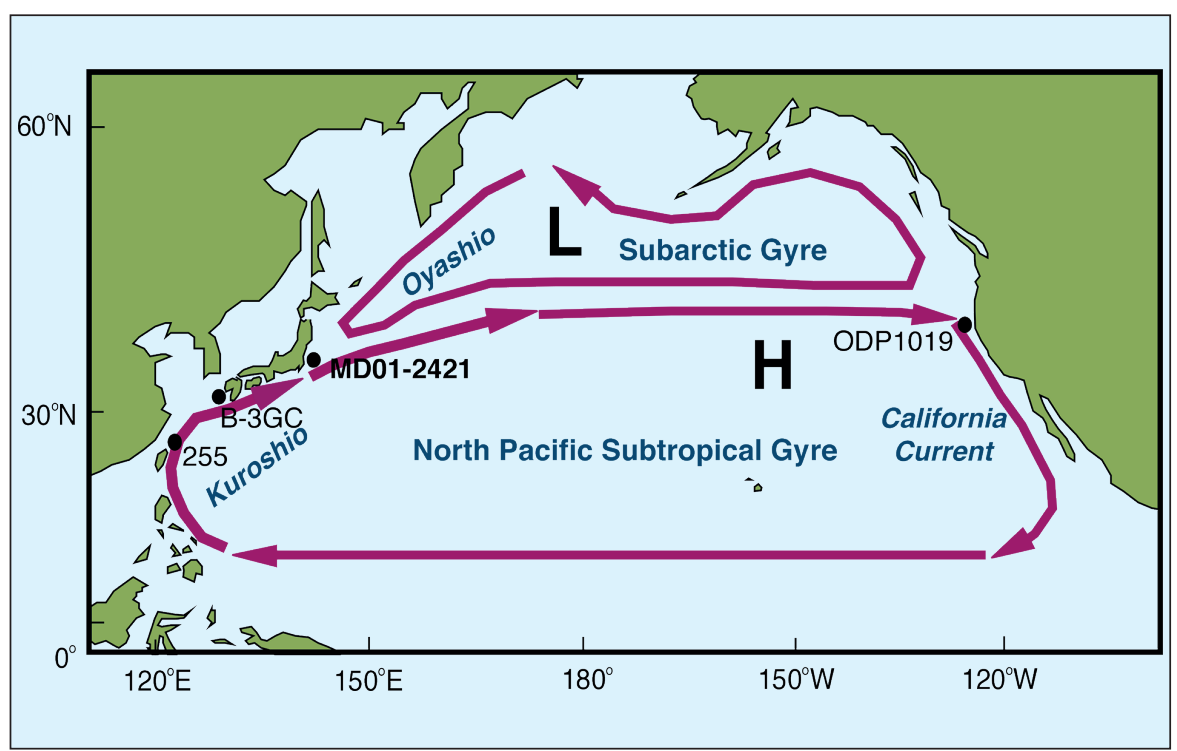

Figure 1: Locations of the study site MD01-2421, and other mentioned reference sites in the North Pacific. The subarctic and subtropical gyre circulations are driven by westerly and trade winds that are regulated by the summer North Pacific High (H) and the winter Aleutian Low (L). Figure modified from Isono et al. (2009).

events, suggesting that the oscillation is paced at warming events. The standard deviation of the last seven warming events is nearly equal to the 130 years identified for glacial DansgaardOeschger (DO) events (Schulz 2002; Rahmstorf 2003). The deviation of the last seven warming events in the Pacific from a regular 1470-year recurrence is about as small as for the deviation of DO events (Rahmstorf 2003; Fig. 2H). This correspondence suggests the existence of a persistent 1470-year cycle during both the Holocene and the last glacial period.

The occurrence of a persistent regular 1500-year cycle in glacial and interglacial modes suggests that it is a response to a periodic external forcing rather than an internal oscillation in the climate system (Rahmstorf 2003). Solar output variations estimated from variations in tree ring $\Delta^{14} \mathrm{C}$ variations (Solanki et al. 2004) do not match the Japan-margin SST variation (Figs. 2A and $2 \mathrm{G}$ ), except for the Little Ice Age when low temperatures at the Japan margin correspond to low solar output. Spectral analysis of solar radiation variation does not show a 1500-year periodicity (Stuiver and Braziunas 1993).
Braun et al. (2005) suggested that a non-linear response of freshwater input into the North Atlantic Ocean to the solar de Vries/Suess and Gleissberg cycles (210- and 87-year periodicities, respectively) is a candidate mechanism for the 1500-year cycle. Their modeling study suggested that some non-linear process might be producing a 1500-year cycle. Debret et al. (2007) distinguished solar forcing of 1000- and 2500-year oscillations from a 1500-year cycle in Holocene records from North Atlantic sediments by wavelets analysis. They attributed the 1500-year cycle to oceanic forcing.

The 1500-year oscillation was subdued in the Holocene, whereas it was amplified and dominant as DO events in the last glacial. This suggests that positive feedbacks operated to amplify the 1500-year oscillation under glacial boundary conditions.

\section{Spatial distribution of the 1500-year cycle}

Modern oceanographic modes indicate that the SST off Japan reflect variations in the North Pacific gyre system, i.e. the Pacific Decadal Oscillation (Mantua et al. 1997) and the North Pacific Gyre 
Oscillation (Di Lorenzo et al. 2008). If such modes operated over millennia, then the 1500-year temperature variation at the Japan margin implies that the North Pacific gyre circulation is affected by 1500 -year cycles. At the northern California margin site ODP 1019, analysis of an alkenone-derived SST record (Fig. 2F; Barron et al. 2003) revealed a broad peak of spectral

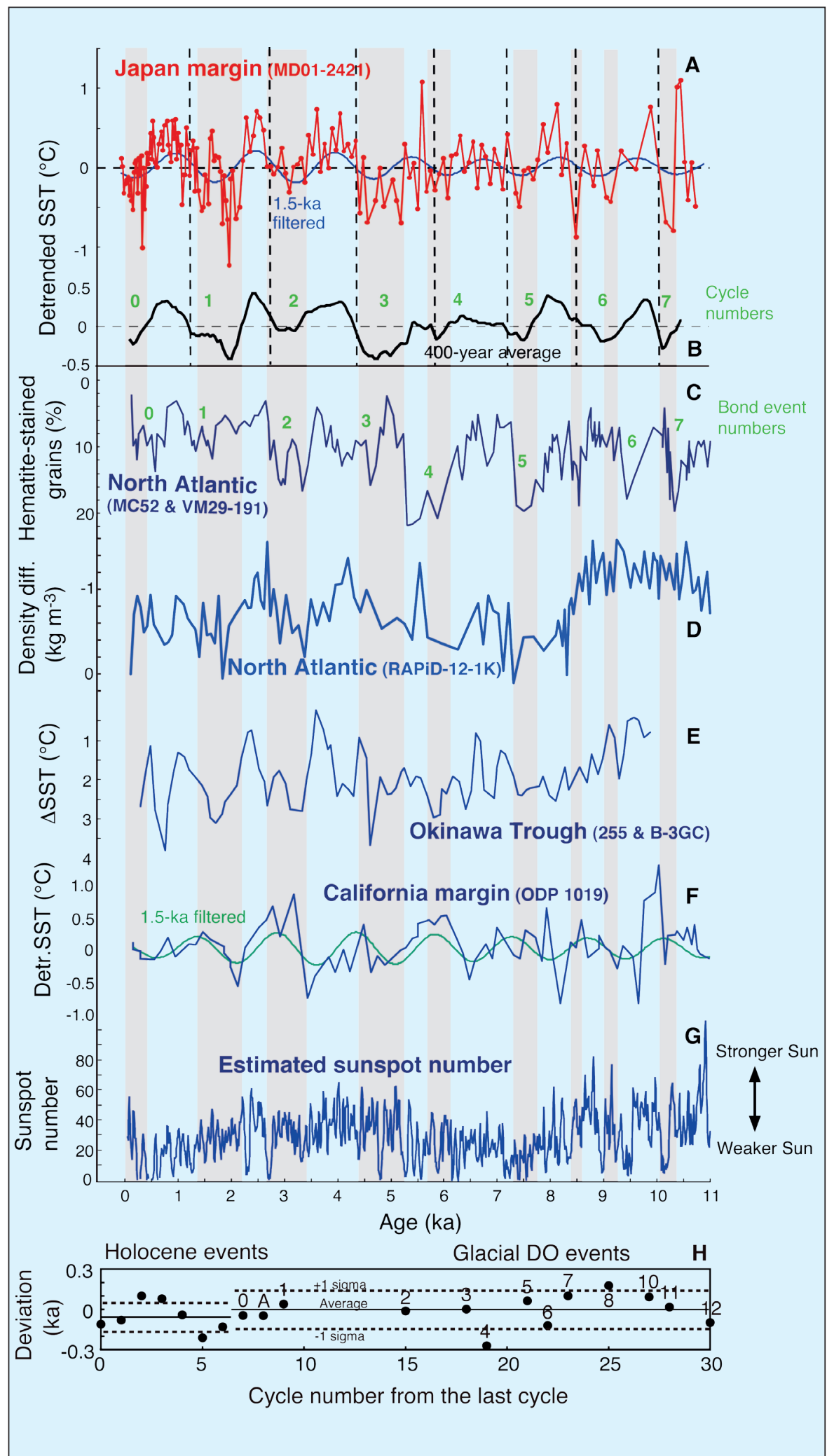

Figure 2: Holocene variations in (A) detrended U $\mathrm{K}^{\prime}$-derived SST at the study site (Isono et al. 2009), (B) its 400-year running mean omitting the cooling event at $8.5 \mathrm{ka},(\mathrm{C})$ hematite-stained grain content in a North Atlantic core (Bond et al. 1997), (D) mixed layer density in the North Atlantic (Thornalley et al. 2009), (E) lateral SST differences in the Okinawa Trough (Jian et al. 2000), (F) detrended UK ${ }^{3}$-derived SST at ODP Site 1019 at the California margin (Barron et al. 2003), and (G) tree-ring $\triangle^{14} C$-based sunspot numbers (Solanki et al. 2004). Gray shading indicates cold periods at the Japan margin. $(H)$ Time deviations from a regular 1470-year template for the mid-point of warmings at site MD01-2421 during the Holocene and at Greenland site GISP2 during the last glacial period (Rahmstorf 2003). Numbers in panel H indicate Dansgaard-Oeschger interstadials; " $A$ " = Allerød. Figure modified from Isono et al. (2009). density with a periodicity range of $\sim 1470$ to 1820 years. The 1470-year variation was coherent with the SST oscillations we found off Japan. Jian et al. (2000) generated foraminifera-based SST records for the northern and southern Okinawa Trough (sites B-3GC and 255) and claimed that the SST difference between the two sites varied with a 1500-year periodicity. However, only the SST minima 1, 2, and 4 at our site MD01-2421 correlate with $\Delta S S T$ maxima at the Okinawa Trough (Fig. 2E). The SST minima at the Japan margin also correlate with Bond events 2, 5, and 7 and partly with events 0,1 , and 3 (Fig. 2C). The Japan margin record shows similarities to the degree of stratification in the subpolar North Atlantic (Fig. 2D; Thornalley et al. 2009). Although none of these correspondences are perfect, they suggest that the southward shift of the Kuroshio Extension jet in the northwestern Pacific was often synchronous with ocean circulation in the North Atlantic.

All of the sites discussed for displaying 1500-year oscillations are sensitive to the northern mid-latitude westerlies, which suggests that the westerlies and subtropical and subarctic gyre dynamics have been involved in propagating or generating 1500-year oscillations in the climate system. However, the forcing of the 1500-year variability and its effect on the climate system in both glacials and interglacials still remain puzzling. Future investigations are necessary to clarify these issues.

\section{Notes}

Data are available from the NOAA Paleoclimatology website www.ncdc.noaa. gov/paleo/paleo.html

\section{Acknowledgements}

I thank Dai Isono, Tomohisa Irino, Tadamichi Oba, Masafumi Murayama, Toshio Nakamura, and Hodaka Kawahata for discussions.

\section{Selected references}

Full reference list online under:

http://www.pages-igbp.org/products/newsletters/ref2012_2.pdf

Bond G et al. (1997) Science 278: 1257-1266 Bond G et al. (2001) Science 294: 2130-2136 Isono D et al. (2009) Geology 37: 591-594

Jian Z et al. (2000) Earth and Planetary Science Letters 184: 305-319 RahmstorfS (2003) Geophysical Research Letters 30, doi: 10.1029/2003GL017115 